\title{
THE MEASUREMENT OF THE NUTRITIONAL LEVEL OF THIAMIN IN CHILDREN BY THE ESTIMATION OF THE URINARY EXCRETION
}

BY

\author{
E. C. AllibONE, M.D. and E. FINCH, M.Sc.
}

(From the Children's Hospital, Birmingham)

The incidence of deficiency syndromes due to lack of the vitamin B complex is low in children living in temperate climates. Nevertheless, doubts have been raised as to whether a dietary intake, sufficient to prevent a frank deficiency state, was optimal for development.

Morgan and Barry (1930) found an increased weight gain on supplementing children's diets with wheat germ. Bloxsom (1929), using yeast, and Dennett (1929), using wheat germ sugar, recorded the same result with infants. Litchfield et al. (1939) found that the weight gain of prematures was accelerated by yeast. Poole et al. (1937) using rice polishings could not detect any acceleration in weight gain although the gain was steadier.

Justin and Helms (1937) supplemented the diet of fifty infants with vitamin B. Over a period of a year there was an increase of height and to a less extent of weight as compared with a similar number of controls. Elias and Turner (1936), using wheat germ and yeast, observed no difference in either height or weight gain, but anorexia was less frequent than in controls. They were of the opinion that added vitamin was unnecessary on a good diet.

From the above reports it may be assumed that, whereas a good diet may contain optimal amounts of vitamin $\mathbf{B}$, this desideratum is often not attained.

Further attempts to determine the nutritional state of the individual with regard to thiamin were made possible when Harris and Leong (1936), by means of the bradycardia method, found the urinary output of thiamin to be dependent on the intake. The publication of the thiochrome method of estimation of thiamin in body fluids and tissues facilitated further study on the relationship between intake and output. Bicknell and Prescott (1942) tabulated the daily urinary excretion of normal adults. The results of nine groups of workers using the thiochrome method, ranged between 50 and 500 microgm. per day.

Benson et al. (1942) found in healthy children a daily excretion of at least 20 per cent. of the intake, the lowest figures being 100 microgm., the average being 270 microgm. per day. These workers considered the estimation of the daily excretion to be preferable to giving a loading dose of pure vitamin as large doses were insensitive and small doses gave too variable results. The daily output of urinary thiamin should be at least 20 per cent. of that ingested. Westenbrink and Goudsmit (1937), however, showed that in normal subjects on a thiamin poor diet for two to three days, the twenty-fourhour secretion fell to 40 microgm., suggesting that the estimation of the dietary excretion without administration of a test dose would in many cases only indicate the adequacy of the diet during the preceding few days. Wang and Yudkin (1940) also showed that the resting level did not give an accurate assessment of the state of nutrition and stipulated test doses for the detection of the presence and degree of deficiency.

For these reasons, coupled with the considerable variation in the excretion of the vitamin in normal subjects, many workers considered the degree of excretion after an oral test dose of 1 to $5 \mathrm{mgm}$. to be the more reliable guide. If large doses were given orally there was a failure of absorption. Ritsert (1938a), after an oral dose of $10 \mathrm{mgm}$. in an adult, found only 4 to 7 per cent. in the urine, there being 7 to 30 per cent. in the faeces. Karrer (1937) also found that the larger the oral dose the smaller the percentage excretion in the urine. A loading dose must therefore bear a close relationship to the needs of the organism.

The daily requirements of children had been variously estimated. Morgan and Haynes (1939) found that a well-fed woman excreted milk containing 32 microgm. of vitamin $B_{1}$ per $100 \mathrm{c.cm}$. Attempts to raise this figure by thiamin supplements to the maternal diet caused a fall in the excretion level to 25 microgm. per $100 \mathrm{c.cm}$. These findings agree with those of Knott, Kleiger and Schlutz (1943) who, from the results of thiamin excretion, considered that infants needed 40 microgm. per kgm. body weight. In older children Knott (1936) found a higher retention accompanying higher levels of intake, 60 microgm. per $\mathrm{kgm}$. per day being the optimum amount. From these figures it would appear that an oral dose of $0.5 \mathrm{mgm}$. to infants and $1.0 \mathrm{mgm}$. to older children would be within physiological limits. The dose is usually given with a meal as Melnick and Field (1939) found that, when thiamin was given on a fasting stomach, less vitamin was excreted, suggesting that some was destroyed 
in it, although a major excretion in the first four hours rather than in the first eight indicated that the thiamin was absorbed more rapidly on an empty stomach.

Hills (1939), who administered a test dose of $1 \mathrm{mgm}$. orally to adults, examined the excretion of vitamin during the next three hours, finding the maximum response during the second hour. Jowett (1940), using a $5 \mathrm{mgm}$. test dose considered the shortest period for collecting urine to be five hours, in which time a constant proportion (68 per cent.) of the twenty-four hour excretion was eliminated in normals although in patients there were greater variations. Borson (1940), who gave 0.1 mgm. per $\mathrm{kgm}$. body weight considered that a normal person excreted 8 to 10 per cent. of the dose within five hours. Ritsert (1938b), however, used twenty-fourhour specimens, as did Melnick et al. (1939), having found delayed absorption of vitamin when given with a meal.

\section{Present investigation}

Type of case investigated. The children, who were in-patients, were drawn mainly from workingclass homes. As the hospital was in a danger area from the point of view of air raids, the earlier cases had to be evacuated as soon as they were fit to travel. The subjects to be tested had to be well enough to be on an ordinary diet, to be reliable in their habits and not to be receiving either salicylates or chemotherapy. This restricted the choice of case. In the majority the test was limited to the collecting of urine on two consecutive days. The following day an oral dose of vitamin $\mathrm{B}_{1}$ was given. Anomalous results unfortunately could not be checked as the cases had by this time either been discharged or evacuated.

In view of the frequent irregularity in absorption and excretion of urine in children, all urine, whether following a test or not, was initially collected in three periods from 6 a.m. to noon, noon to 6 p.m. and from 6 p.m. to 6 a.m.

Method. The urinary thiochrome was estimated after the method of Janson (1936). Wang and Harris (1939) have examined many possible sources of error and some of their modifications were used. The interference caused by non-specific fluorescent substances present in children's urine was very pronounced in many specimens. Their suggestion for a preliminary washing with iso-butyl alcohol certainly reduced this interference in many cases but in others there was left a fluorescence which produced such a high blank that the estimation had to be abandoned. It was found later that some of this fluorescence was due to the use of corks in the extraction tubes. The use of glass-stoppered flasks reduced this trouble considerably. A photo-electric fluorimeter was used for the measurement of the fluorescence. The tubes used to hold the fluorescent liquid were selected to give the minimum fluorescence in ultra-violet light when empty and all had practically the same small value in this respect. They were $1.9 \mathrm{~cm}$. in diameter, this larger size having been found necessary to produce a reasonable deflection with urine specimens frequently low in thiamin. Iso-butyl alcohol was used for the final clearance of the solutions. The use of filter paper was avoided by centrifuging whenever necessary. No sodium sulphate was used.

Specimens were collected in stoppered bottles containing $10 \mathrm{c.cm}$. of glacial acetic acid for twentyfour hours and proportional amounts for shorter periods. If cloudy or showing a precipitate, a portion was centrifuged and the clear upper layer used for the estimation. If very concentrated and dark, it was mixed with an equal volume of water. A known aliquot, usually 10 c.cm., was shaken thoroughly with an equal volume of iso-butyl alcohol for at least a minute. After centrifuging, the volume of the aqueous layer was noted and then carefully removed. Three lots of $2.5 \mathrm{c} . \mathrm{cm}$. of the urine were then transferred to three large test-tubes of $50 \mathrm{c} . \mathrm{cm}$. capacity and $7.5 \mathrm{c} . \mathrm{cm}$. of distilled water were added to each. To tubes 1 and $2,3 \mathrm{c.cm}$. of 14 per cent. caustic soda were added and to tube 2 a solution of 1 per cent. potassium ferricyanide was immediately added with shaking and drop by drop until there was just an excess as indicated by a slight increase in the yellow colour. To tube 3 was added $0.2 \mathrm{c} . \mathrm{cm}$. of a solution of thiamin containing $1 \mathrm{mgm}$. per $100 \mathrm{c} . \mathrm{cm}$., followed by caustic soda and ferricyanide as in tube 2. After two minutes' standing, $12.5 \mathrm{c} . \mathrm{cm}$. of iso-butyl alcohol were added to each tube and it was stoppered and shaken fairly gently for two minutes, afterwards standing till clear. $10 \mathrm{c.cm}$. of the iso-butyl alcohol layer were pipetted off from each tube and transferred to the fluorimeter tube. $1 \mathrm{c.cm}$. of dry ethyl alcohol was added to each tube to clarify. The readings were then made in the fluorimeter and the thiamin calculated. Tube 3 was used to determine the recovery value after addition of a standard quantity of thiamin. This usually ranged from 90 to 100 per cent. with an average of 94 to 95 per cent. The standard was prepared as follows. A solution containing $100 \mathrm{mgm}$. of thiamin in $100 \mathrm{c.cm}$. of water containing 2 drops of concentrated hydrochloric acid was prepared and diluted ten times. $1 \mathrm{c.cm}$. contained 100 microgm. To $1 \mathrm{c.cm}$. of this solution $3 \mathrm{c.cm}$. of 10 per cent. sodium hydroxide were added and 2 drops of 1 per cent. potassium ferricyanide. After standing for two minutes it was extracted with $20 \mathrm{c.cm}$. iso-butyl alcohol to give suitable dilutions in a volume of $9 \mathrm{c.cm}$. and $1 \mathrm{c.cm}$. of ethyl alcohol was added to clear. These tubes were read in the fluorimeter and a curve plotted of the galvanometer readings against the concentration of thiamin.

Since at low dilutions and with the apparatus in use the deflection is proportionate to the concentration, we have in the following work used only those concentrations within this range of dilutions, viz., between 0.1 and 0.4 microgm. per c.cm. Hills (1939) found that 'provided the thiamin content was not great, it was linearly related to the fluorescence of the oxidised extracts.'

Results. The twenty-four-hour urinary excretion showed a range of 10 to 400 microgm. Lower values were obtained in the younger age groups who had a lower calorie and vitamin intake. When the age groups were rendered comparable by expressing the excretion as a percentage of the intake the differences became less, ranging from an average of 10 per cent. in the youngest age group to 14 per cent. in the oldest (table 1).

ORAL LOADING TEST. Sixty-seven children were given an oral dose of 0.5 to $1.0 \mathrm{mgm}$. thiamin. The amount of this excreted in the following twentyfour hours varied from 0 to 41 per cent., with an average of $14 \cdot 1$ per cent. There was a considerable 
scatter. Twenty-seven children excreted more than the average as against forty who excreted less. Although the proportion of the dietary thiamin excreted resembled that of the loading dose in many cases, individual variations were so great that there was no statistically significant relationship between the percentage thiamin excretion from the loading dose and that from the dietary intake in the preliminary period.

\begin{tabular}{|c|c|c|}
\hline $\begin{array}{l}\text { VERAGE D } \\
\text { EXPRESSED }\end{array}$ & $\begin{array}{c}\text { TABLE 1 } \\
\text { AILY EXCRETIO } \\
\text { AS A PERCEN } \\
\text { DIETARY INT }\end{array}$ & $\begin{array}{l}\mathrm{J} \text { OF } \\
\text { AGE } \\
\text { KE }\end{array}$ \\
\hline $\begin{array}{c}\text { Number } \\
\text { of cases } \\
14 \\
18 \\
25 \\
22\end{array}$ & $\begin{array}{c}\text { Range of age } \\
\text { in years } \\
0-3 \\
3-6 \\
6-10 \\
10-13\end{array}$ & $\begin{array}{c}\text { Average per- } \\
\text { centage excretion } \\
10 \cdot 0 \\
12 \cdot 7 \\
12 \cdot 5 \\
14 \cdot 0\end{array}$ \\
\hline
\end{tabular}

EXCRETION PERIOD FOR ORAL TEST. In the first forty-six tests the urine was collected for twentyfour hours in three periods of six, six and twelve hours. When the cases were grouped according to the proportion of the total excretion which occurred in the initial six- and twelve-hour periods, it was found that in only eleven cases was there at least 80 per cent. of the total excretion in the first specimen of urine (table 2).
TABLE 2

DISTRIBUTION OF CASES TO SHOW THE PROPORTION OF THE TOTAL EXCRETION FOLLOWING A TEST DOSE COLLECTED BY THE END OF SIX AND TWELVE HOURS

\begin{tabular}{c|c|c}
\hline $\begin{array}{c}\text { Percentage of } \\
\text { total 24-hour } \\
\text { excretion }\end{array}$ & \multicolumn{2}{|c}{ Number of cases } \\
\cline { 2 - 3 } & $\begin{array}{c}\text { at the end of } \\
\text { six hours }\end{array}$ & $\begin{array}{c}\text { at the end of } \\
\text { twelve hours }\end{array}$ \\
\hline Over 80 & 11 & 27 \\
$60-80$ & 15 & 13 \\
$40-60$ & 16 & 5 \\
$20-40$ & 4 & 1 \\
\hline
\end{tabular}

There was no relationship between the amount of the oral dose voided in twenty-four hours and the rate at which it was excreted during this period.

As the urine had to be collected for a minimum period of twelve hours following an oral dose of thiamin given with a meal in order to obtain the greater part of the vitamin excreted, urines were subsequently collected for twenty-four hours as a single sample.

A few cases received a parenteral injection of vitamin, the dose being half that of the oral. Even greater variations in the amounts excreted were noted than with the single oral dose.

TABLE 3

EXCRETION OF DIETARY THIAMIN IN CERTAIN DISEASE CONDITIONS WITH THE RESULTS OF SUCCESSIVE DAILY ORAL LOADING DOSES IN THESE AND OTHER STATES

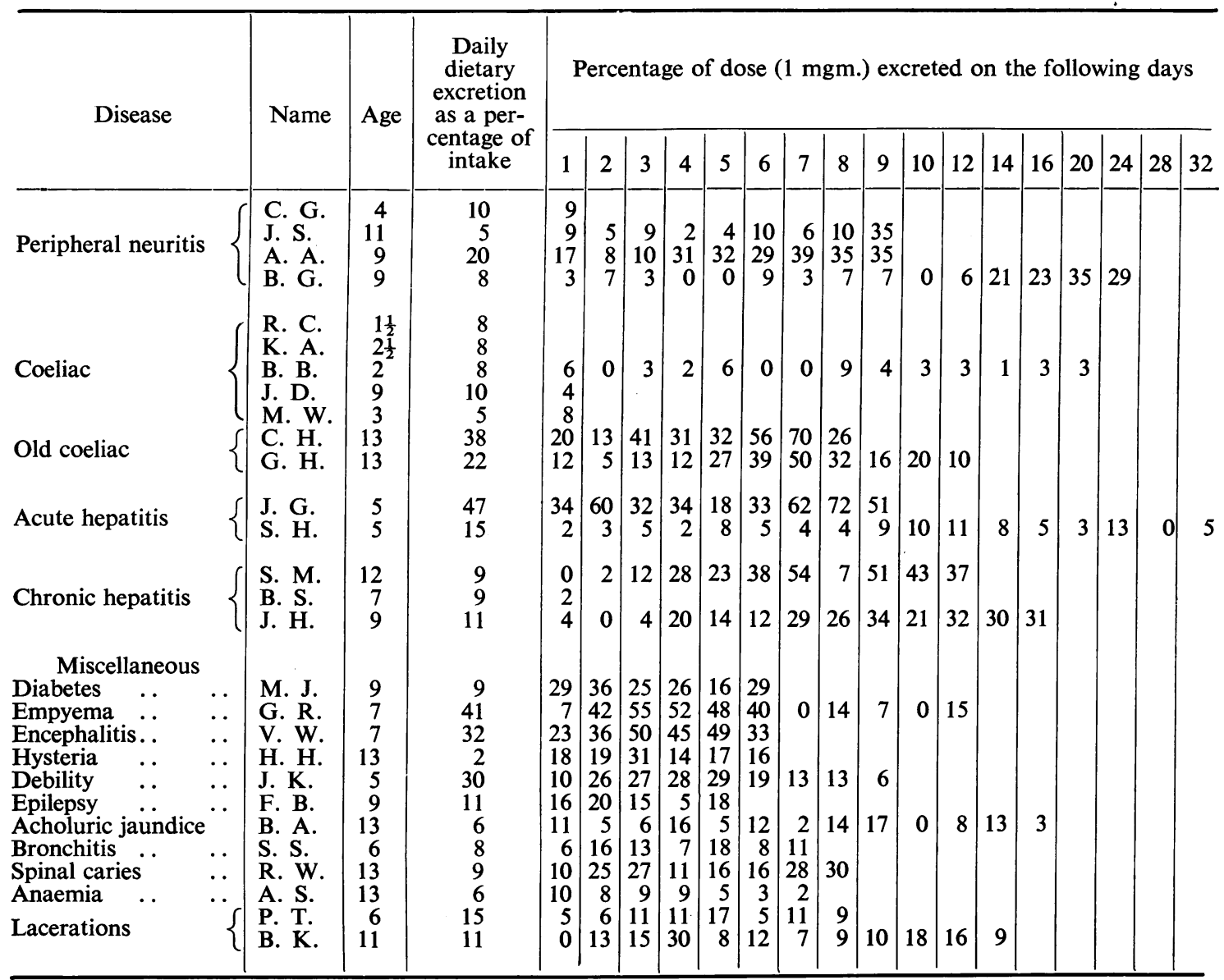


Twenty-two of the later cases received successive oral doses of vitamin daily. The resulting curves could be grouped into five types. There were eight straight-line graphs showing daily excretions of less than 13 per cent. (fig. 6). At the other extreme there were four cases showing a relatively high biapical curve (fig. 1), in which even the lowest point

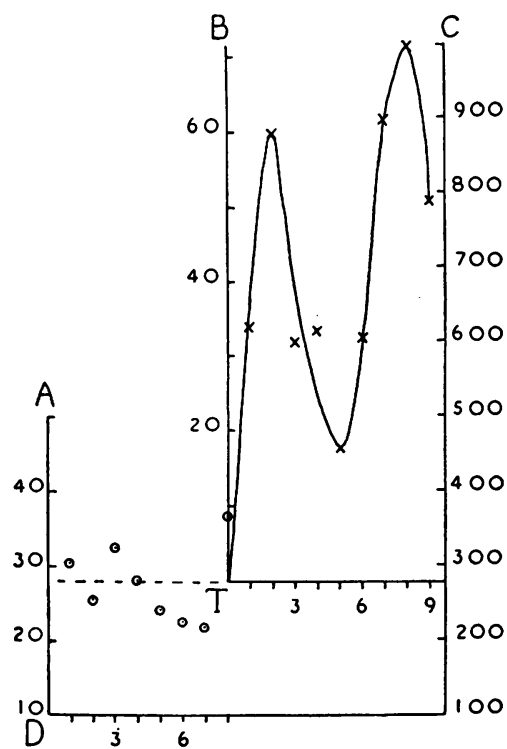

FIG. 1.-A bicuspid curve. J. G., a case of acute hepatitis.

Ordinates A. Percentage of dietary thiamin excreted. B. Percentage excretion of test dose. C. Actual daily excretion in microgm.

Abscissae D. Period of determination of dietary thiamin output in days. T. Period over which a daily test dose of $1 \mathrm{mgm}$. of thiamin was given.

of the curve was above the average excretion of the preliminary period. This configuration had previously been observed by Baucke (1939). Intermediate were eight cases giving steeply rising curves with and without an initial lag (fig. 2 and 3). In three of these cases where the dose was continued past the peak there was a rapid fall in the excretion

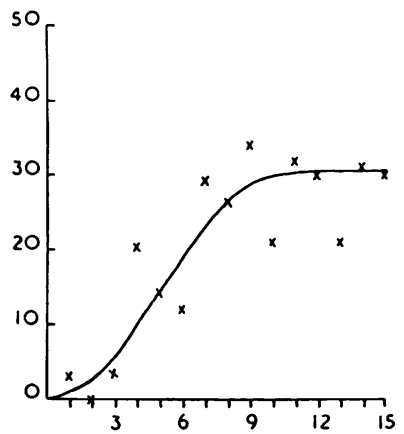

Fig. 2.-Curve showing rapid rise after an initial lag in the urinary excretion of a loading dose of $1 \mathrm{mgm}$. thiamin given on successive days. J. H., a case of hepatic cirrhosis.

Ordinates. Percentage of loading dose excreted. Abscissae. Days. (fig. 4 and 7). Finally there was one curve which rose only slowly after a long initial lag.

One case, C. H., with a steep curve following successive doses of $1 \mathrm{mgm}$. thiamin, received $12.0 \mathrm{mgm}$. thiamin subcutaneously on alternate days. On the day of the injection 7 to $8 \mathrm{mgm}$. was excreted. On the rest days the output was about

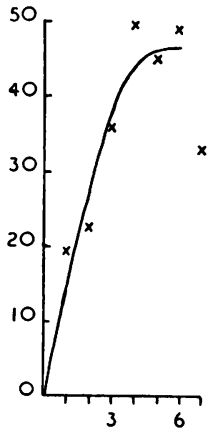

FIG. 3.-Curve showing an immediate and rapid rise following successive oral doses of $1 \mathrm{mgm}$. thiamin. V. W., a case of recent encephalitis.

Ordinates. Percentage of loading dose excreted. Abscissae. Days.

1.0 mgm., which when compared with the average daily dietary excretion of $\mathbf{4 0 0}$ microgm. over a preliminary period of eight days, indicated a spillover from the day before. If this single example can be taken to be representative it shows that neither the mechanism of luxury consumption (v. Drigalski, 1939) nor the renal tract can cope immediately with unphysiological doses.

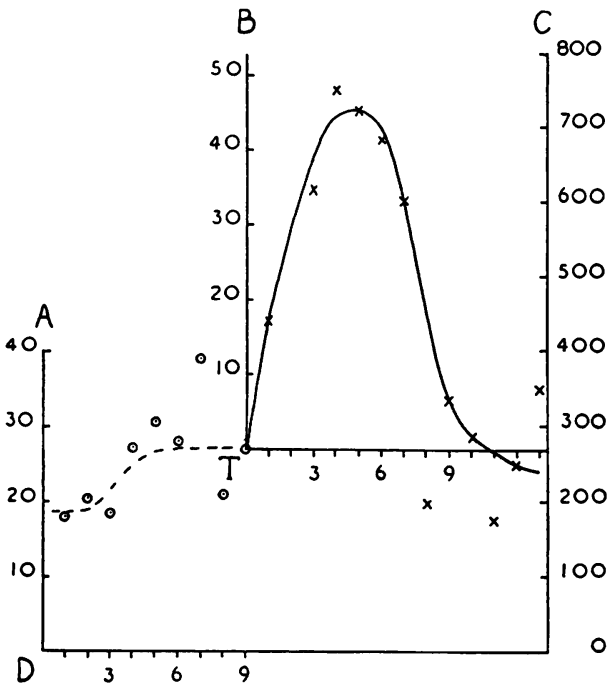

FIG. 4.-Curve showing rapid rise and fall in the excretion of thiamin following successive oral loading doses of $1 \mathrm{mgm}$. G. R., a case of recent empyema.

Ordinates A. Percentage of dietary thiamin excreted. B. Percentage excretion of test dose. C. Actual daily excretion in microgm.

Abscissae D. Period of determination of dietary thiamin output in days. T. Period over which a daily test dose of $1 \mathrm{mgm}$. of thiamin was given. 


\section{Discussion}

The results of the average daily excretion of vitamin were lower than those of Benson et al. (1941), who found in healthy children an average daily excretion of 27 per cent. of the intake. The following figures compare their diets with the results of the present investigation:

$\begin{array}{lccccc} & \begin{array}{c}\text { Pro- } \\ \text { tein } \\ (\mathrm{gm} .)\end{array} & \text { Fat } & \begin{array}{c}\text { Carbo- } \\ \text { hydrate }\end{array} & \begin{array}{c}\text { Calories } \\ \text { (gm.) }\end{array} & \begin{array}{c}\text { Intake } \\ \text { of B } \\ (\mathrm{mgm} .)\end{array} \\ \text { Benson et al .. } & 85 & 96 & 236 & 2159 & 0.99 \\ \text { Present figures } & 76 & 94 & 207 & 1980 & 1.0\end{array}$

The discrepancy in the daily excretion is not to be explained by a difference between the calories or the calculated vitamin intake. The American children attended the hospital solely for the purpose of the test whereas ours had all been admitted for some form of therapy. Forty-seven out of seventynine cases had had a recent pyrexial illness, particularly the smaller children. All those in the youngest age group had been recently pyrexial. When Benson et al. (1942) also used cases which had had a recent infection they obtained lower results very similar to ours.

If the dietary excretion were estimated over consecutive days there was often a considerable fluctuation from day to day (fig. 4). The proportion of the loading dose excreted was calculated by subtracting the average dietary excretion of two or more previous days from the actual total output of vitamin. The recordings of the excretion of the loading dose were therefore modified by any variation in the dietary excretion. It follows that isolated determinations of the dietary output have a limited value and of an isolated loading dose even less. When the nutritional state of an individual is to be studied it is desirable to stabilize both diet and fluid intake. The amount of milk and bread should be constant. Other foods rich in thiamin, e.g. bacon, which tend to be given sporadically should be eliminated or given regularly. A restricted fluid intake produces a concentrated urine containing a high degree of interfering fluorescent substances which produce a high blank. Fluid in excess of normal requirements dilutes the vitamin in the urine to a degree that it is difficult to measure. It was not found that a polyuria increased the vitamin excretion. The patient should, in addition, not be receiving any absorbable drug of the sulphonamide group or salicylate. To obtain reliable results the dietary output should be estimated over a period of about a week and the loading doses for a further eight to ten days.

Sciclounoff (1939) reported four cases of vitamin B deficiency which eliminated the vitamin and two cases with no signs which excreted none. He concluded that the estimation of the urinary thiamin was not a reliable index of the degree of saturation. It is proposed to consider the results of successive oral doses in the light of this criticism.

Cases producing a rapid rise in excretion must either be near saturation point or be unable to utilize the thiamin. In the three cases G. H., G. R. (fig. 4) and J. K. (fig. 7) where the loading dose was continued past the peak excretion there followed a rapid fall in output. This may indicate that the organism had at first only a limited ability to utilize the vitamin, an improvement developing during the course of the experiment. An alternative interpretation would be that the organism adjusts itself to the overloading with vitamin by disintegrating it

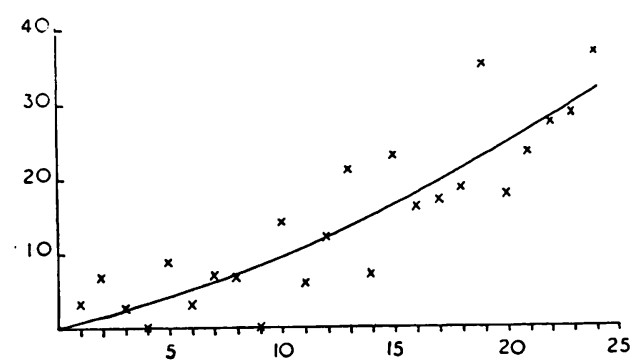

FIG. 5.-Slowly rising curve. B. G., a case of postdiphtheritic polyneuritis.

Ordinates. Percentage of oral loading dose excreted. Abscissae. Days.

in the metabolism without using it for its physiological purpose. This phenomenon was called luxury consumption by v. Drigalski (1939). On the other hand, if one excepts the case of S. H., who had a haemolytic anaemia in addition to the hepatitis and which will be referred to later, the three other cases of hepatitis (table 3) had a persistently high excretion of the oral loading dose indicating either a persisting inability to metabolize the vitamin or a complete saturation. Similar high excretions have been observed in adult cases of liver damage (Sydenstricker, personal communication).

The eight cases, whose graph showed a straight line, all had a low excretion of 13 per cent. or less. It is probable that most of these would have eventually shown a gradual rise if continued longer, as occurred with B. G. (fig. 5). However, four cases,

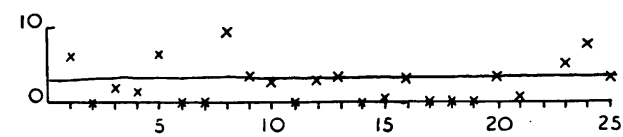

Fig. 6.-A flat curve. B. B., a case of coeliac disease. Ordinates. Percentage of oral loading dose excreted. Abscissae. Days.

B. K., B. A., B. B. and S. H. showed flat curves after 14, 18, 28 and 33 days respectively (fig. 6). B. B. was a coeliac and failure of absorption seemed the likeliest reason in this case. Parenteral injections were given to B. B. over consecutive days without any appreciable result during the eleven days of the test (table 4). Again the probable cause was a high degree of unsaturation consequent on failure of absorption. B. A. was a case of acholuric jaundice, S. H. a case of sub-acute atrophy of the liver complicated by the presence of pan-agglutinins acting at body temperature. In both cases there 
had been, immediately prior to the vitamin assay, evidence of a haemolytic process. It is known (Sinclair, 1939) that haemin destroys thiamin. It is possible that other breakdown products of haemoglobin have a similar effect. Jansen, quoted by Schroeder (1939), considers that slight amounts of haemolysed blood cells cause the disappearance of thiamin from the blood. B. K. was a case of fractured femur, there was no apparent clinical cause for such a graph and no suggestion can be made for the low excretion in this case. A persistently low curve must mean either a failure of absorption or an increased utilization or destruction and signifies a deficiency without indicating the cause. But all the cases show that a marked unsaturation may be present without clinical symptoms of thiamin deficiency.

\section{TABLE 4}

PERCENTAGE EXCRETION OF THIOCHROME AFTER SUCCESSIVE DAILY PARENTERAL DOSES OF 0.5 MGM. VITAMIN $B_{1}$ TO A CASE OF COELIAC DISEASE

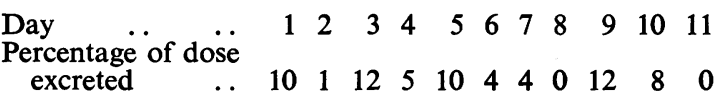

The slowly rising curves after successive loading doses also indicate a deficiency though of rather less degree. This type of curve is the most suggestive for an under saturation which becomes repaired by the intake. A similarly patterned curve may be seen during the period of determination of the dietary excretion prior to giving the loading dose (fig. 7). The rapid rise after an initial lag (fig. 2)

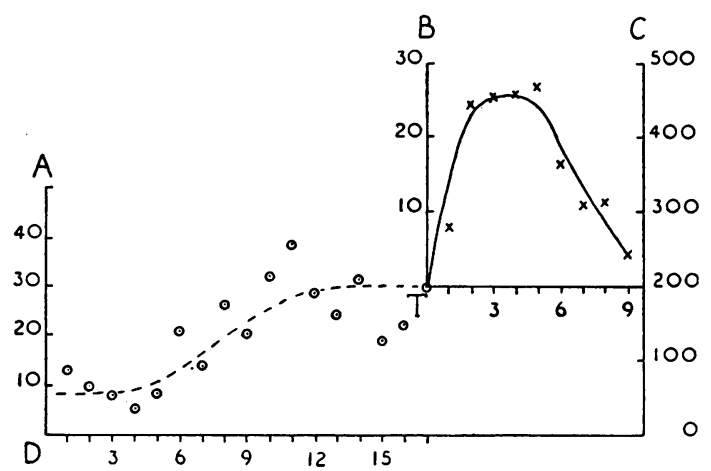

FIG. 7.-Effect of giving repeated doses of $1 \mathrm{mgm}$ thiamin after stabilisation on the ward diet. J. K., a case of debility.

Ordinates A. Percentage of dietary thiamin excreted. B. Percentage excretion of test dose. C. Actual daily excretion in microgm.

Abscissae D. Period of determination of dietary thiamin output in days. T. Period over which a daily test dose of $1 \mathrm{mgm}$. of thiamin was given.

also suggests a deficiency (Wang and Harris, 1939), though naturally less severe than in the case of the slowly rising curve. In the case J. H., shown in fig. 2 , the dietary excretion had been determined for only two days prior to giving the loading doses and averaged 11 per cent. of the intake. It seems likely that if no loading doses had been given until dietary stabilization had occurred, a graph similar to that seen in fig. 7 would have resulted.

Within the limits above defined, the oral loading dose applied over successive days may give information as to whether the body has been absorbing the optimum amount and whether it is capable of utilizing it. To this extent it is not possible to agree with the views of Sciclounoff. No claim is made that the test gives any indication of the clinical state. In the present series no case of beriberi was recognized, though it is interesting to speculate whether the cases of peripheral neuritis owed a degree of their severity to a previous subclinical deficiency.

It is probable that the body can adjust itself to wide ranges of intake. Meyers (1941) found in the Javanese on a high carbohydrate diet of polished rice with little fat that the average urinary excretion of thiamin was low though beri-beri was rare. He suggested a possible adaption to a long-standing low vitamin $B$ intake for the low incidence of clinical deficiency.

A further explanation of anomalies between the amount of intake and the presence and severity of symptoms is the formation of vitamin by biosynthesis. Najjar and Holt (1943) found that four out of nine individuals on a thiamin free diet did not develop beri-beri and that these four excreted considerably more free thiamin in the stools than did the five with symptoms of beri-beri. This faecal excretion diminished when the bacterial flora was reduced by succinyl sulphathiazole.

The above points, coupled with the English standard of living, are sufficient to explain the rarity of symptoms suggesting a deficiency.

\section{Summary}

The results of the estimation of urinary thiochrome in a group of eighty children are described.

The relative value of estimations of dietary excretion and following isolated and consecutive loading doses of thiamin is discussed.

Although many recently ill children excreted reduced amounts of thiamin no symptoms which could be directly attributed to beri-beri were found even in the most severely depleted.

Thanks are due to Prof. L. G. Parsons, Dr. E. M. Hickmans and to Dr. H. S. Baar for their kind help and advice, and to the Honorary Staff of the hospital for permission to use their cases. One of us (E. F.) was in receipt of a grant from the Medical Research Council which has also defrayed the expenses of the laboratory work.

\section{REFERENCES}

Baucke, J. (1939). Klin. Wschr., 18, 1128.

Benson, R. A., Witzberger, C. M., and Slobody, L. B. (1941). J. Pediat., 18, 617.

—, Slobody, L. B., Witzberger, C. M., and Lewis, L. (1942). Ibid., 20, 454.

Bicknell, F., and Prescott, F. (1942). The Vitamins in Medicine, London.

Bloxsom, A. P. (1929). Amer. J. Dis. Child., 37, 1161. 
Borson, H. J. (1940). Ann. intern. Med., 14, 1.

Dennett, R. H. (1929). J. Amer. med. Ass., 92, 769.

Drigalski, W. v. (1939). Klin. Wschr., 18, 99.

Elias, H. L., and Turner, R. (1936). J. Pediat., 8, 352.

Harris, L. J., and Leong, P. C. (1936). Lancet, 1, 866.

Hills, G. M. (1939). Biochem. J., 33, 1966.

Janson, B. C. P. (1936). Rec. Trav. chim. Pays Bas, 55, 1046.

Jowett, M. (1940). Biochem. J., 34, 1348.

Justin, C. Z., and Helms, S. T. (1937). Arch. Pediat., $54,533$.

Karrer, W. (1937). Helv. chim. Acta, 20, 1147.

Knott, E. M. (1936). J. Nutrit., 12, 597. Kleiger, S. C., and Schlutz, F. W. (1943). J Pediat., 22, 43.

Litchfield, H. R., Lichtermann, J., Knott, J., and Kurland, J. (1939). Amer. J. Dis. Child., 57, 546.

Melnick, D., Field, H. Jr., and Robinson, W. D. (1939). J. Nutrit., 18, 593.

Meyers, F. M. (1941). Amer. J. med. Sci., 201, 785.
Morgan, A. F., and Barry, M. M. (1930). Amer. J. Dis. Child., 39, 935 .

Morgan, A. F., and Haynes, E. G. (1939). J. Nutrit., $18,105$.

Najjar, V. H., and Holt, L. E., Jr. (1943). J. Amer. med. Ass., 123, 683.

Pollack, H., Ellenberg, M., and Dolger, H. (1941). Arch. intern. Med., 67, 793.

Poole, M. W., Hamil, B. M., Cooley, T. B., and Macy, I. G. (1937). Amer. J. Dis. Child., 54, 726.

Ritsert, K. (1938a). Klin. Wschr., 17, 1397.

- (1938b). Dtsch. med. Weschr., 14, 481.

Schroeder, H. (1939). Klin. Wschr., 18, 148.

Sciclounoff, F. (1939). Schweiz. med. Wschr., 29, 665.

Sinclair, H. M. (1939). Proc. roy. Soc. Med., 32, 807.

Wang, Y. L., and Harris, L. J. (1939). Biochem. J., 33. 1356.

Wang, Y. L., and Yudkin, J. (1940). Ibid., 34, 343.

Westenbrink, H. G. K., and Goudsmit, J. (1937). Rec. Trav. chim. Pays Bas, 56, 803. 